\title{
Delayed Arterial Switch Operation in a Three Year Old Child with Transposition Of Great Arteries
}

Huseyin Avni Solğun ( $\nabla$ hsynavn@gmail.com )

Altinbas Universitesi https://orcid.org/0000-0001-6811-4600

\section{Farid Gojayev}

Altinbas Universitesi

\section{Case report}

Keywords: Arterial switch(Jaten) operation, delayed operation, transposition of great arterieas (TGA)

Posted Date: November 1st, 2019

DOI: https://doi.org/10.21203/rs.2.16709/v1

License: (9) This work is licensed under a Creative Commons Attribution 4.0 International License. Read Full License 


\section{Abstract}

Background: The incidence of transposition of the great arteries (TGA) is $0.5-1 \%$ of all congenital heart diseases. The aorta and pulmonary arteries exit inversely from the heart ventricles. In addition, $25 \%$ of TGA patients have ventricular septal defect (VSD). Some infants may have left ventricular outflow tract obstruction. Arterial switch (Jaten) operation is the accepted procedure for the treatment of TGA.

Case report: The patient had congenital severe cyanosis and was diagnosed as TGA, VSD and ASD after a pediatric cardiology examination. The patient went to follow-up for a short time and did not go to follow-up and admitted to our institute with complaints of severe cyanosis and decreased exercise capacity at the age of 34 months. According to echocardiography and angiography findings, arterial switch operation (AS) was planned for treatment despite delayed treatment.

Conclusion: In general; it is preferable to perform AS in the first month of life in patients with TGA. There is very rare information in the literature about the preferability of early childhood patients. In the light of this information, we present a case of successful atrial switch operation in a three-year-old patient.

\section{Background}

In order to maintain life in TGA, circulating blood must be mixed in the heart or elsewhere before complete correction. Blood mixing is critical to the protection of life. VSD, atrial septal defect (ASD) or patent ductus arteriosus (PDA) is very important in these patients to allow blood to be mixed naturally. If this mixing is not possible naturally, an emergency catheterization or atrial septostomy (AS) is required (1). It is generally preferred for the first 3 weeks in the neonatal period for AS surgery. It is often not possible to perform AS operation when this time is delayed. To perform delayed correction, palliative cardiac surgery should be performed first (2). In this study; having previously undergone pulmonary bunding; A 3-year-old boy with TGA diagnosed with VSD and ASD is presented.

\section{Case Presentation}

The patient, who had severe cyanosis since birth, was diagnosed as TGA, VSD and ASD by pediatric cardiology examination in another hospital. Palliative surgery was planned to the patient who was followed up with medical treatment until eight months ago and then referred to our institute for further examination and treatment. Pulmonary bunding and surgical procedures were performed and the patient was discharged. When the patient was 34 months old, he was admitted to our institute again with complaints of severe cyanosis and decreased exercise capacity. Echocardiography and angiography were performed. The pulmunary gradient was $68 \mathrm{mmHg}$ (figure 1). Atrioventricular intercourse was normal, cardiac cavities were normal and ventricular contractions were normal. No ventricular wall hypoplasia was detected. Valvular morphology was normal. No coronary abnormality was detected in angiography (3). Pulmonary catheterization did not show pulmonary hypertension (figure 2). 
AS surgery was planned. Cardiopulmonary bypass (CPB) was performed at 32 degrees Celsius. During the cooling period of the $\mathrm{CPB}$, the right and left pulmonary arteries were channeled towards the hilus entry and the patent ductus arteriosus was divisible. Antegrade route has been used in blood cardioplegia to protect myocardial tissue. Debunding of pulmonary arteries, arteriotomy and supravalvular fibrous membrane resection were performed respectively. VSD was continued with right arteriotomy and patch suturing technique. Vulvular dilatation was performed with 17 plugs. Valvular leakage was tested after enlargement and no valvular insufficiency was detected. AS Leevte maneuver was performed. After neoaorta and coronary artery anastomosis, the second dose of cardioplegia was given. Before Neopulmunar anastomosis; anastomosis leakage, fullness and position of the coronary arteries were observed (Figure 3).

Perfusion adequacy was tested by observing coronary sinus-induced cardioplegia. After neoaortal and coronary anastomosis, bovine patch reconstruction of distal neopulmunar arteries was performed. After completion of the distal anastomosis, aortic bone was opened. Neopulmonary anastomosis was performed with $7 / 0$ prolene suture, while cardiac functions returned (Fig. 4). ASD was fixed with large bovine patch. A small opening is left for the patent foramen ovale (PFO) mechanism to continue. The atrium was re-closed and the inotropic agents dopamine and adrenaline started intravenous infusion. The operation was completed after the sternum was closed again. The aortic cross-clamp time was 62 minutes and the CPB time was 112 minutes, respectively. Postoperative inotropic dopamine was continued and extubation was performed after 5 hours. Sinus rhythm was sufficient in cardiac monitoring and ventricular functions were sufficient in echocardiography.

\section{Discussion And Conclusions}

In the treatment of TGA; first in 1959 and 1963, respectively, Senning and Mustard modifications were made. Various complications related to the use of these modifications have been limited. Currently Jaten operations are the main recommendation in these patients.Arterial switch operation is a globally preferred method for total anatomical correction of TGA and was first performed by Jaten et al. Later modified by Lecompte in 1975.

If the pathological condition is not suitable for performing AS operation; Pulmonary bunding, Rastelli operation, Atrial switch, Damus-Stansel-Key or Nikaidoh operations are also preferable. $(4,5)$.Survival is not more than 1 year in patients without early surgical treatment. Left ventricular pressure and contraction are the main factors for success in simple TGA surgery with intact ventricular septum. Physiologically, pulmonary vascular resistances (PVR) are high in the first 2 weeks of life, so left ventricular functions remain normal. After 15 days of life, PVR drops and left ventricular function will be against low pressure. Over time, left ventricular function will be insufficient $(6,7)$.

Therefore, in patients with delayed treatment, left ventricular function will be against high systemic vascular resistances, so heart output will be low and inotropic agents may be needed. In the literature, operation is recommended if left vetricular stroke volume and wall thickness is normal and left / right 
pressure ratio is higher than 0.70 . In developed countries, delayed cases are rare, but are more common in developing countries for a number of reasons. As in our case, patients who did not undergo AS operation in the neonatal period; Pulmonary banding and shunting is recommended. This procedure provides better post-ventricular load performance to prepare the patient for subsequent AS surgery. The time taken to improve left ventricular performance is inversely proportional to the age of the patient. If palliative pulmonary banding is performed for 3 weeks, it will be sufficient even in older people up to 3 months ago. In developed countries, in recent years, direct surgery is recommended for patients under 3 months of age. In childhood; pulmonary hypertension is another factor related to morbidity and mortality of complex TGA patients $(8,9)$.

In conclusion, although our case was 34 months old, ASO operation was performed successfully. If palliative operation was performed in early neonatal period and secondary left ventricular functions and dimensions were within normal limits, pulmonary hypertension did not develop and angiographic coronary artery anomaly was not observed in TGA cases; even at 3 years of age, arterial switch operation can be performed easily. In our case, arterial switch operation was successfully performed at 34 months of age. We present the successful outcome of surgical treatment in patients with delayed surgical treatment because it is very rare in the literature.

\section{Abbreviations}

TGA: Total anamolous of great arteries

VSD: Ventriculer septal defect

ASD: Atrail septal defect

AS: Atrial switch operation

PDA: Patent ductus arteriosus

CBP: Cardiopulmunarry bypass

PFO: Patent foramen ovalis

PVR: Pulmunary vasculer resistance

\section{Declarations}

Ethics approval and consent to participate have been taken from Altınbas Unıversıty Medicine School Ethical Committie

Consent for publication have been taken from the patients' parents. Patient's parents gave informed written consent for their personal or clinical details along with any identifying images to be published in 
this study.

Availability of data and material statementNot applicable

Competing interests None declerated

Funding None declareted

Authors' contributions Author Huseyin Avni Solgun and Farid Gojayev have read and approved the manuscript

Acknowledgements The authors are thankfull to all indivuduals have contributed to this study.

\section{References}

1.Transposition of the great arteries.Miyazaki T, Kado H.Kyobu Geka. 2004 July; 57 (8): 711-6. Japan

2.Arterial switch operation in neonates with complex congenital heart defects. Wojtalik M, Sharma G, Mrowczynski W, Siwinska A, Henschke J, Bartkowski R, Pawelec-Wojtalik M, Piaszczynski M.Asian Cardiovasc Thorac Ann. 2003 March; 11 (1): 14-7

3.Arterial switch operation for transposition of the great arteries with coronary arteries from a single aortic sinus. Sung SC, Chang YH, Lee S, Kim S, Woo JS, Lee YS.Ann Thorac Surg. 2005 August; 80 (2): 636-41.

4.Treatment options for transposition of the great arteries with ventricular septal defect complicated by pulmonary vascular obstructive disease. Alakhfash AA, Tamimi, Al-Khattabi AM, Najm HK. J Saudi Heart Assoc. 2009 July; 21 (3): 187-90. doi: 10.1016 / j.jsha.2009.06.008. Epub 2009 August 5.

5.Enhanced left ventricular training in corrected transposition of the great arteries by increasing the preload. Zartner PA, Schneider MB, Asfour B, Hraska V. Eur J Cardiothorac Surg. 2016 Jun; 49 (6): 15716. doi: 10.1093 / ejcts / ezv416. Epub 201527 Nov.

6.Echocardiographic screeining of pulmonary hypertension in congenital hearth diseases. JACC journal, issue of the week.

7.Haemodynamic characterisation and heart catheterisation complications in children with pulmonary hypertension: Insights from the Global TOPP Registry (tracking outcomes and practice in paediatric pulmonary hypertension). Beghetti M, Schulze-Neick I, Berger RM, Ivy DD, Kaporta D, Weintraub RG, Saji T, Yung D, Mallory GB, Geiger R, Berger JT, Barst RJ, Humpl T; TOPP İnvestigators. Int J Cardiol. 201615 Jan, 203: 325-30. doi: 10.1016 / j.ijcard.2015.10.087. Epub 201523 Oct.

8.Long-term Management of the Arterial Switch Patient. Kirzner J, Pirmohamed A, Ginns J, Singh HS.Curr Cardiol Rep. 2018 Haz 26; 20 (8): 68; doi: 10.1007 / s11886-018-1012-9. 
9.Update on the Management of Adults With Arterial Switch Procedure for Transposition of the Great Arteries.Safi LM, Bhatt AB.Curr Treat Options Cardiovasc Med. 2017 Jan; 19 (1): 4 doi: 10.1007 / s11936-017-0505-y.

\section{Figures}

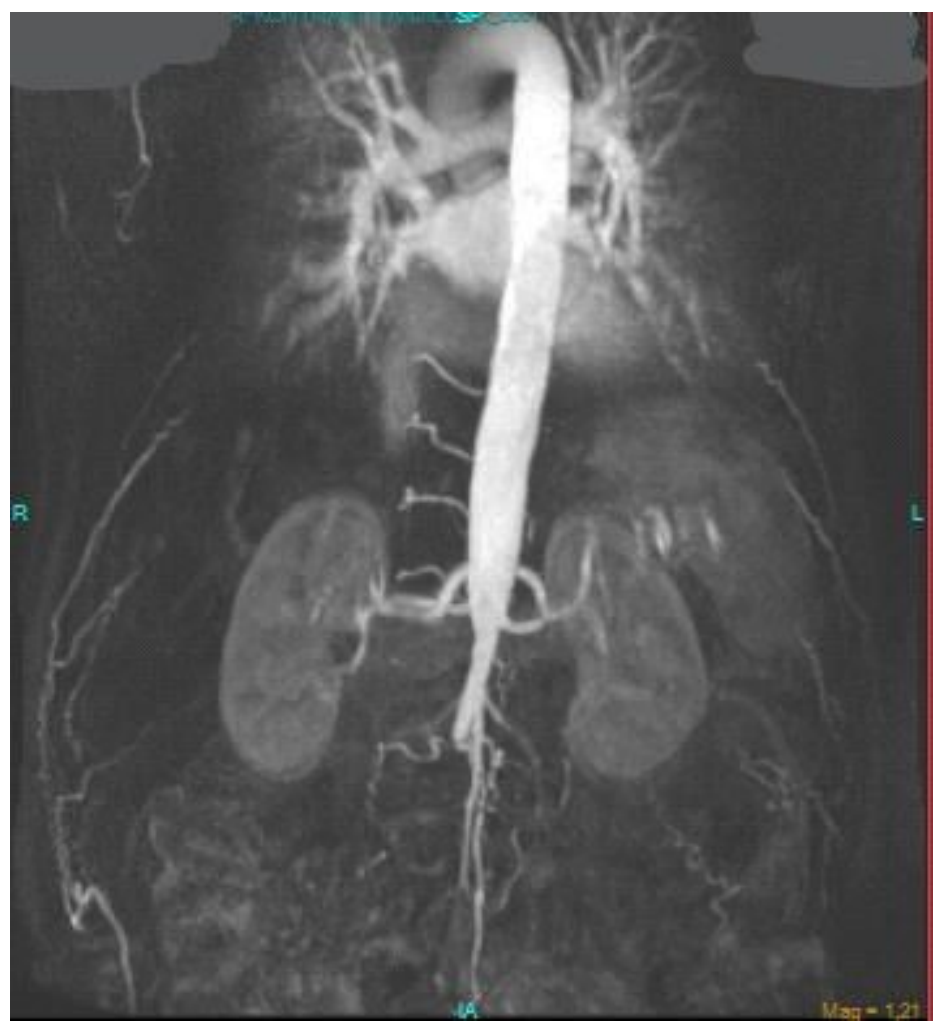

\section{Figure 1}

Total infrarenal aortailiac occlusion 


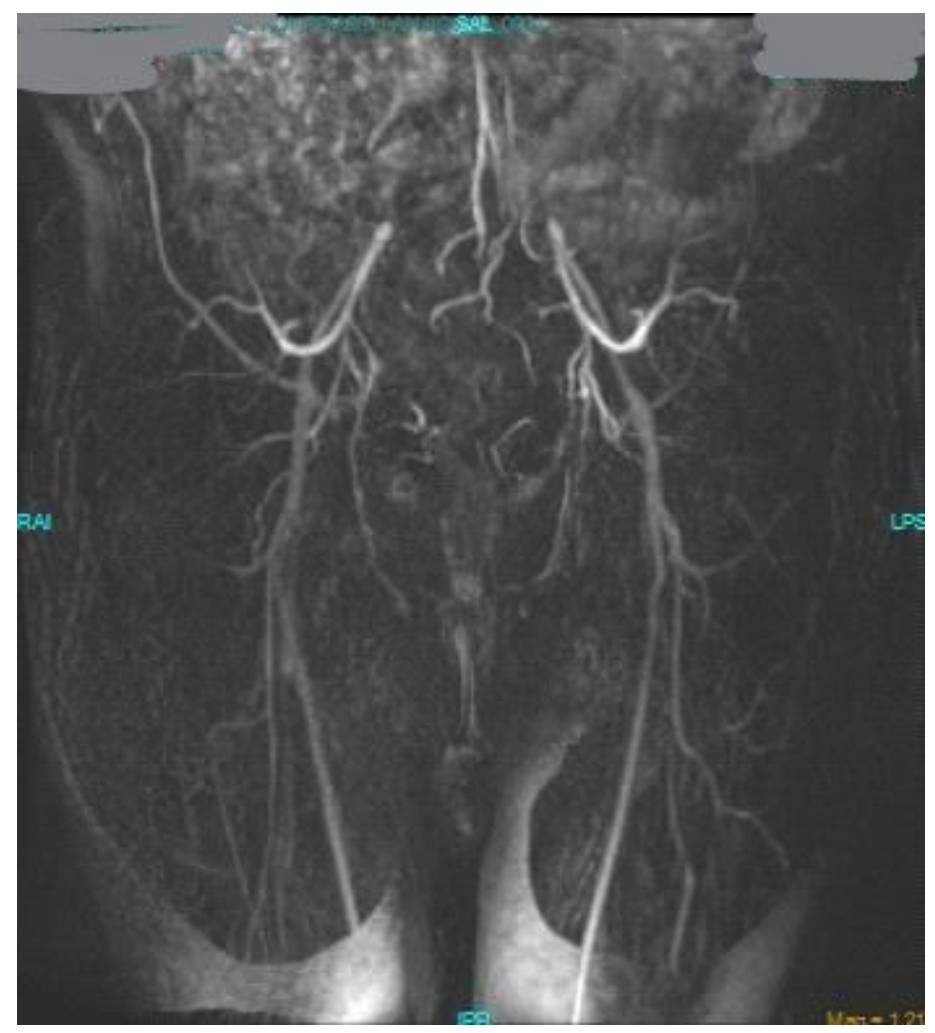

Figure 2

Total infrarenal aortailiac occlusion

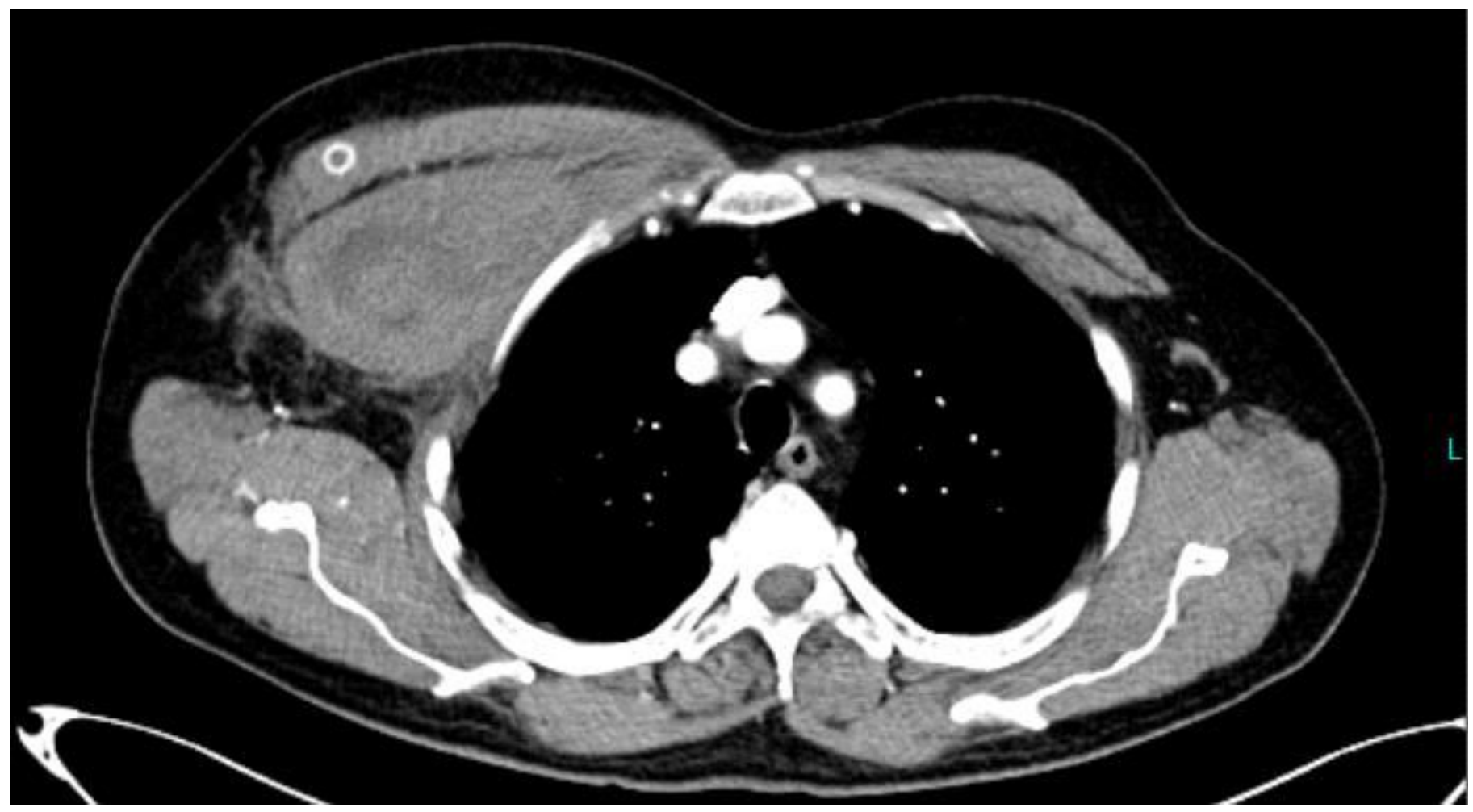

Figure 3

Laseration and hematoma of graft in anastomosis line 


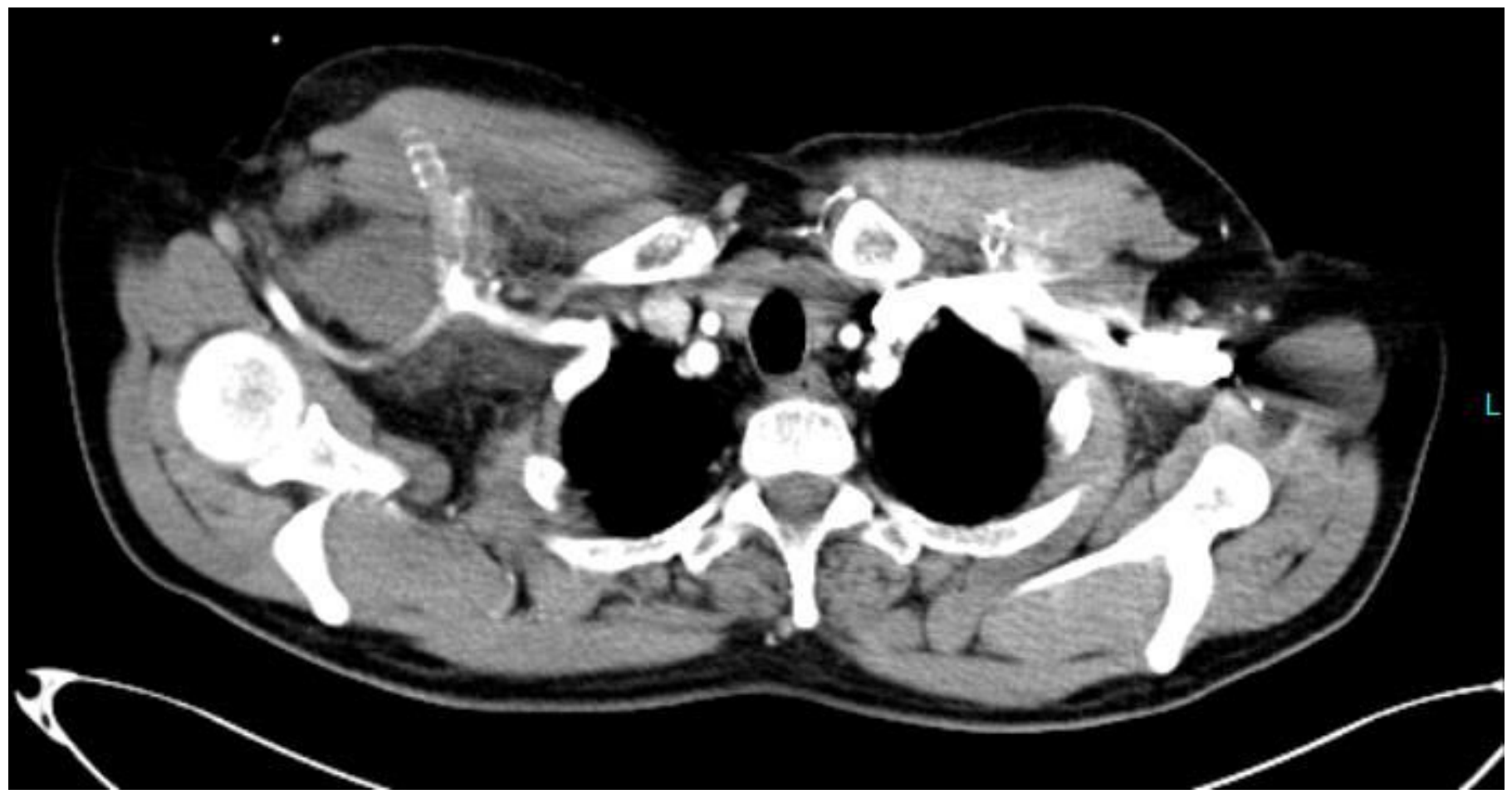

Figure 4

Hematoma and graft view of pektoral muscle

\section{Supplementary Files}

This is a list of supplementary files associated with this preprint. Click to download.

- CareChecklist.JPG 